\title{
Formation and stability of polysomes and polysomal populations in roots of germinating seeds of soybean (Glycine max L.) under cold, osmotic and combined cold and osmotic stress conditions
}

\author{
Sylwia Swigonska $\cdot$ Anna Badowiec $\cdot$ Agnieszka Mostek \\ Angelika Krol $\cdot$ Stanisław Weidner
}

Received: 7 June 2013/Revised: 14 September 2013/Accepted: 15 November 2013/Published online: 6 December 2013

(C) The Author(s) 2013. This article is published with open access at Springerlink.com

\begin{abstract}
Abiotic stress factors such as extreme temperatures or osmotic stress are among the major causes of inferior crop yields. In response to a stress, plants have evolved various defense mechanisms. In our study, we have demonstrated how cold stress, osmotic stress and a combination of both stresses retard the growth of roots and inhibit the process of ribosomes binding into polysomes. The tested stresses also limited the ability of root tissues to synthesize proteins. At the same time, most of the analyzed samples were found to contain elevated shares of the fractions of cytoskeleton-bound polysomes (CBP, CMBP) in the total population of polysomes. Using a polysomebased degradation system, it was shown that polysomes formed under stress conditions were much more resistant to the effect of exogenous ribonuclease than the control ones. The highest tolerance to digestion was demonstrated by the cytoskeleton-bound (CBP) and cytoskeleton-membrane bound polysomes (CMBP). The increasing share of CBP and their stability in roots of seeds germinating under stress conditions can be a target for physiological regulation. It seems that modifications in the stability and percentages of
\end{abstract}

Communicated by S. Abe.

S. Swigonska · A. Badowiec · A. Mostek · A. Krol ·

S. Weidner

Department of Biochemistry, Faculty of Biology and Biotechnology, University of Warmia and Mazury in Olsztyn, Oczapowskiego Street 1a, 10-957 Olsztyn, Poland

Present Address:

S. Swigonska $(\square)$

Research and Education Center 'Laboratory of Molecular Diagnostics', Faculty of Biology and Biotechnology, University of Warmia and Mazury in Olsztyn, Prawochenskiego Street 5, 10-720 Olsztyn, Poland

e-mail: sylwia.swigonska@uwm.edu.pl particular polysomal populations play an important role in the adaptation of plants to stress conditions, which may indicate that these forms of polysomes, i.e., cytoskeletonbound ones, are involved (via selective translation) in the synthesis of stress proteins in soybean roots.

Keywords Cytoskeleton-bound polysomes . Cytoskeleton-membrane-bound polysomes .

Germination - Polysomal stability · Osmotic stress · Cold stress $\cdot$ Soybean roots

\section{Introduction}

Many commercially valuable crops today grow far away from the zones of their natural occurrence. This creates a risk of plants being exposed to climatic conditions which are completely different from the ones required by particular plant species. Soybean appears to be an ideal model for analyzing relationships between the climate and yielding success. The expansion of soybean, which is a plant of the subtropical climate, has reached climatically extreme regions such as Scandinavia, Canada or Siberia (Funatsuki et al. 2003).

Soybean has become an important crop in human and animal nutrition mainly because of its well-balanced composition of amino acids in protein and the content of several highly valuable nutrients, e.g., polyunsaturated fatty acids, vitamins and minerals. The twentieth century science and technology defined the significance of this crop, while the contemporary biotechnology and development of new techniques will most probably determine the scope of its future use (Gardner and Payne 2003). The crucial economic role of soybean means that uncovering the mechanisms which regulate its growth and 
development, especially under less favorable weather conditions, turns into a key task of the contemporary agricultural sciences. Although advanced genomic and postgenomic research on plants like Arabidopsis thaliana provide a wealth of information on the mechanism evoked in plants by stress conditions, much of this information does not apply to the biology of leguminous plants (Cánovas et al. 2004).

Genetic information contains the instruction on the building up of proteins, which are responsible for most of the functions performed in the cell. The mechanism of protein synthesis known as translation is much more complicated than replication or transcription.

Translation involves simultaneous participation of numerous ribosomes. When several ribosomes are bound to a single mRNA molecule, a polysome is formed. In plant cells, some of polysomes can appear in the free form. Free polysomes (FP) suspended in the cytoplasm participate in the synthesis of cytoplasm soluble proteins, the cellular nucleus, mitochondria and peroxisomes (Zambetti et al. 1990). Another form of polysomes found in plant cells consists of polysomes bound to the rough endoplasmic reticulum (MBP). Under a microscope, clusters of membrane-bound polysomes create a grain-like image. Polysomes do not bind to the reticulum permanently. Contrary to that, they dissociate from the ER membranes once the protein synthesis is terminated and bind to it only on commencement of the synthesis of proteins (Bewley et al. 2013). Bonds between polysomes and the cytoskeleton were first observed in plant cells in the early 1990s. Populations of the cytoskeleton-bound polysomes (CBP) were noticed by Davies et al. (1991), and their presence in plant tissues was verified by other researchers (e.g., Weidner and Łukaszewicz 1997; Zak et al. 1997). At first, it was suspected that polysomes from the CBP fraction bound to actin filaments (Davies et al. 1993; Zak et al. 1997). Nowadays, it is known that mediator proteins are involved in the binding of polysomes to the cytoskeleton (Klyachko et al. 2000, 2003). How polysomes attach to the cytoskeleton has not been fully recognized yet, but it is suspected that the CMBP fraction polysomes function as an element part of an apparatus regulating translation and attached to actin filaments distributed over the surface of cellular membranes (Davies et al. 1998). Attachment of polysomes to the cytoskeleton might ensure correct spatial arrangement of the translational machinery and protein synthesis activation. If the binding of polysomes to the cytoskeleton is considered an additional level of protein synthesis regulation, its physiological control can be expected (Klyachko et al. 2003). This means that efficiency of protein biosynthesis is guaranteed not only by polysomes but also by elements stabilizing and regulating spatial interactions between components of the translation apparatus.
Control of gene expression is exerted by an intricate network of numerous pathways involving transcription, post-transcriptional RNA modification and processing, rate of nucleocytoplasmic transport and translation, transcript stability and localization. RNA processing is an important component of the regulated gene expression in eukaryotic cells. The rates of transcription, pre-mRNA splicing, mRNA transport, translation and degradation, determine the steady-state amount of mRNA, and consequently the amount of protein, which will be available to the cell (Knapińska et al. 2005). The stability of particular mRNA is controlled by a specific interaction between its structural elements and RNA-binding proteins, which can be general or mRNA-specific. Regulated mRNA stability is achieved through fluctuations in half-lives in response to developmental or environmental stimuli (Guhaniyogi and Brewer 2001). Accumulation of defence mRNA is a response of plants to stress (e.g., Eulgem 2005). However, increased transcription of a gene during a stress response does not ensure its translation into a protein product. It is therefore important to consider the possibility of translational control when distinguishing between components of biotic and abiotic plant stress responses. It seems that mechanisms regulating mRNA stability are as numerous as the ones involved in mRNA synthesis (Chiba and Green 2009). Coordinated regulation of these two processes guarantees that cells are highly adaptable.

To achieve a better distinction between the mechanisms involved in the cellular degradation of eukaryotic mRNA a polysome-based degradation system was developed to investigate the stability of polysomes and their particular fractions in soybean roots during seed germination under abiotic stress conditions.

\section{Materials and methods}

Plant material and growth conditions

The plant material used in this experiment consisted of seeds of the common soybean (Glycine max L.) cultivar 'Aldana', purchased in Strzelce (Poland). The analyzed material was composed of roots isolated from germinating soybean seeds. Seeds were surface sterilized in $0.5 \%$ sodium hypochlorite for $20 \mathrm{~min}$ and washed with sterilized water. Then, they were placed on Petri dishes $13 \mathrm{~cm}$ in diameter and lined with a double layer of filter paper. Control samples were germinated for $24,48,72$ or $96 \mathrm{~h}$ in $+25{ }^{\circ} \mathrm{C} /$ water (C). For simulation of cold and osmotic stresses, seeds were divided into four groups germinating under the following conditions: cold stress, $+10{ }^{\circ} \mathrm{C} /$ water (CS); osmotic stress, $+25^{\circ} \mathrm{C} /-0.2 \mathrm{MPa}(\mathrm{OS})$ and cold stress combined with osmotic stress, $+10{ }^{\circ} \mathrm{C} /-0.2 \mathrm{MPa}$ 
(COS). Germination of seeds at different temperatures was accomplished in an incubator manufactured by Sanyo (MIR 154). To stimulate osmotic stress of $0.2 \mathrm{MPa}$, polyethylene glycol was used (molecular weight 8,000, made by Sigma) at a concentration of $119.46 \mathrm{~g} / \mathrm{l}$ for germination at temp. $+25^{\circ} \mathrm{C}$ and $99.68 \mathrm{~g} / \mathrm{l}$, when the germination temperature was $+10^{\circ} \mathrm{C}$. Once the set germination time was over, roots of germinated seeds were collected, immediately frozen in liquid nitrogen and kept in $-80{ }^{\circ} \mathrm{C}$ for further analysis.

\section{Polysome isolation and quantification}

The root tissue (400 $\mathrm{mg}$ ) was homogenized in $3 \mathrm{ml}$ of cytoskeleton-stabilizing buffer C (Abe and Davies 1991), filtered and centrifuged at 27,000 $\times g$ for $10 \mathrm{~min}$. Buffer $\mathrm{C}$ consisted of $5 \mathrm{mM}$ HEPES, $10 \mathrm{mM} \mathrm{Mg}(\mathrm{OAc})_{2}, 2 \mathrm{mM}$ EGTA, $1 \mathrm{mM}$ PMSF adjusted to $\mathrm{pH} 7.5$ with $9.8 \mathrm{mM}$ $\mathrm{KOH}$. This buffer enables sequential isolation of four polysome populations (Davies and Abe 1995): FP, MBP, CBP and CMBP. The supernatant polysomes included FP. To prevent their degradation by RNase, the samples were adjusted to buffer $\mathrm{U}$, consisting of $200 \mathrm{mM}$ Tris- $\mathrm{HCl}, \mathrm{pH}$ 8.5, $50 \mathrm{mM} \mathrm{KOAc,} 25 \mathrm{mM} \mathrm{Mg}(\mathrm{OAc})_{2}, 2 \mathrm{mM}$ EGTA, $100 \mathrm{mg} / \mathrm{ml}$ heparin, $2 \%$ PTE (polyoxyethylene-10-tridecyl ether, a non-ionic detergent) and $1 \%$ sodium deoxycholate (Abe et al. 1992) by adding $1 / 4$ vol. of $4 \times$ concentrated buffer $U$ and held on ice prior to further processing. The remaining polysomes were in the pellet and were sequentially solubilized as follows. The pellet was resuspended in $3 \mathrm{ml}$ of buffer $\mathrm{C}+0.5 \%$ PTE to disrupt membranes, centrifuged for $10 \mathrm{~min}$ at $27,000 \times g$ to leave MBP in the supernatant (again converted to buffer $U$ to maintain polysome integrity). All the other polysomes remained in the pellet. This pellet was next resuspended in $3 \mathrm{ml}$ of buffer $\mathrm{C}+200 \mathrm{mM}$ Tris- $\mathrm{HCl}, \mathrm{pH} 8.5$ to disrupt the polysome-cytoskeleton interaction and centrifuged for $10 \mathrm{~min}$ at $27,000 \times g$ to leave CBP in the supernatant (again converted to buffer $U$ ). The final pellet was resuspended in $4 \mathrm{ml}$ of $1 \times$ concentrated of buffer $U$ and re-centrifuged to release the CMBP. All supernatant fractions (FP, MBP, CBP, CMBP) were layered on a $0.5 \mathrm{ml}$ 'pad' of $50 \%(\mathrm{w} / \mathrm{v})$ sucrose in buffer B (50 mM Tris- $\mathrm{HCl}, \mathrm{pH} 7.5,20 \mathrm{mM}$ KOAc, $10 \mathrm{mM} \mathrm{Mg}(\mathrm{OAc})_{2}$ and centrifuged for $90 \mathrm{~min}$ at $300,000 \times g$ in Beckman 65 Ti rotor. The polysomal pellets were rinsed with water and then resuspended in $0.5 \mathrm{ml}$ of buffer $\mathrm{U}$. The resuspended polysomes were centrifuged at maximum speed (approx. $27,000 \times g$ ) for $5 \mathrm{~min}$ in a microfuge prior to layering $0.1-0.2 \mathrm{ml}$ aliquots (about 15 OD units) on linear 15-60\% (w/v) sucrose gradients in buffer B and centrifuged at $300,000 \times g$ in an SW-41 Beckman rotor for $45 \mathrm{~min}$. Gradients were next scanned at $254 \mathrm{~nm}$ on UV-5 flow recorder (ISCO, Lincoln, NE, USA) to display subunits, monosomes and polysomes. All operations were conducted at $0-4{ }^{\circ} \mathrm{C}$. Roots of germinated soybean seeds were also homogenized in buffer $U$ (Abe et al. 1992) to solubilize total polysomes. The subunits, monosomes and polysomes were purified (using $50 \%$ sucrose pad) and the resuspended polysomes were layered on linear 15-60\% sucrose gradients and centrifuged in the same way as mentioned above.

Levels of polysomes were determined by measuring the area under the polysomal profile after subtracting the gradient baseline OD (absorbance of the gradient loaded with $0.1-0.2 \mathrm{ml}$ of resuspension buffer). Quantitation of the ribosomes was done assuming that the absorbance of a $1 \%$ solution of ribosomes (measured in a cuvette with a $1 \mathrm{~cm}$ optical pat at $260 \mathrm{~nm}$ ) equals 135 (Gualerzi and Cammarano 1969).

Analysis of polysomal degradation

Total ribosomal fractions and polysomal populations (FP, MBP, CBP and CMBP) were isolated (using $U$ and $C$ buffers, as explained above) from soybean root tissues after seed germination under control, stress-free conditions and under stresses. The samples were treated with RNase A $(0.05 \mathrm{mg} / \mathrm{ml}$; Sigma). The polysome pellets were solubilized in $0.5 \mathrm{ml}$ of buffer $\mathrm{U}$ and centrifuged for $5 \mathrm{~min}$ at $27,000 \times g$. Polysome suspensions thus prepared were distributed into six Eppendorf tubes ( $0.1 \mathrm{ml}$ each). The content of half tubes was not treated with any enzyme (control samples), whereas $0.5 \mu \mathrm{l}$ RNase A was added to the three remaining tubes (Weidner et al. 2006). After shaking, the contents of all six tubes were layered on sucrose gradients (from 15 to $60 \%$ ) and centrifuged at $300,000 \times g$ for 45 min. After centrifugation, gradients were scanned at $254 \mathrm{~nm}$ on a UV-5 flow recorder (ISCO, Lincoln, NE, USA) to display subunits, monosomes and polysomes. All operations were conducted at $0-4{ }^{\circ} \mathrm{C}$. Polysome profiles were analyzed and RNase-treated compared with control samples.

\section{Results}

All the soybean seeds submitted to analyses belonged to the same cultivar, originated from the same harvest and were stored under identical conditions. The initial studies concerned changes caused by abiotic stresses in roots of germinating seeds. Mean lengths of roots from the control sample and from stress-exposed seeds are set in Table 1. During the first $24 \mathrm{~h}$, the mean length of roots in the control sample was $7 \mathrm{~mm}$. In seeds exposed to stresses, the germination rate dynamics was weaker than in the control. The mean length of roots after $24 \mathrm{~h}$ of cold stress was 
Table 1 Average length of roots isolated from soybean seeds germinating for 24, 48, 72 and $96 \mathrm{~h}$ in optimal conditions (C), and long-term continuous cold stress (CS), osmotic stress (OS) and cold stress combined with osmotic stress (COS)

\begin{tabular}{lllll}
\hline Time $(\mathrm{h})$ & \multicolumn{2}{l}{ Average root length $(\mathrm{cm})$} & & \\
\cline { 2 - 5 } & $\mathrm{C}$ & CS & OS & COS \\
\hline 24 & $0.70 \pm 0.02$ & $0.40 \pm 0.02^{* *}$ & $0.10 \pm 0.01^{*}$ & $0.05 \pm 0.01^{*}$ \\
48 & $1.80 \pm 0.03$ & $0.51 \pm 0.01^{* *}$ & $0.25 \pm 0.01^{* *}$ & $0.23 \pm 0.02^{* *}$ \\
72 & $3.41 \pm 0.02$ & $0.70 \pm 0.01^{* *}$ & $0.72 \pm 0.02^{* *}$ & $0.70 \pm 0.03^{* *}$ \\
96 & $5.30 \pm 0.05$ & $1.70 \pm 0.02^{* *}$ & $1.50 \pm 0.02^{* *}$ & $1.22 \pm 0.05^{* *}$ \\
\hline
\end{tabular}

Data are presented as mean $\pm \mathrm{SD}$

Asterisks represent statistically significant differences at $* p<0.05$ or $* * p<0.01$

shorter than the control and equalled $4 \mathrm{~mm}$. In the samples exposed to osmotic stress or a combination of cold and osmotic stress, the length of roots after the first day of germination did not exceed $1 \mathrm{~mm}$ (Table 1). Later, an increase in the length of roots was observed in all the samples. After $96 \mathrm{~h}$ of germination, the control seeds grew roots with an average length of $5.3 \mathrm{~cm}$. Although germination was seen to advance in all the stress-exposed samples, the mean root length after $96 \mathrm{~h}$ of germination was significantly smaller than in the control, reaching $1.70 \mathrm{~cm}$ in the CS, $1.50 \mathrm{~cm}$ in OS and $1.22 \mathrm{~cm}$ in COS sample (Table 1).

The effect of stresses on changes in the fresh matter of roots of germinating soybean seeds is illustrated in Fig. 1. In the control sample, the fresh mass of roots increased steadily throughout the whole experiment and reached 10 , 34, 66 and $72 \mathrm{mg}$ recalculated per root mass after 24, 48, 72 and $96 \mathrm{~h}$, respectively. Gradual accumulation of fresh matter was also recorded in samples submitted to stresses, but there it was limited by the unfavorable external conditions. After $24 \mathrm{~h}$ germination, no significant differences were detected in the content of fresh matter of roots between seeds germinating under optimal conditions and the ones suffering from abiotic stresses. Statistically significant differences in the root content of fresh matter (versus the control) were demonstrated from the second to the fourth day of germination (Fig. 1). In the sample of seeds exposed to germination under cold stress (CS), the respective amounts of fresh matter of roots after 48,72 and $96 \mathrm{~h}$ of germination were 27, 42 and $33 \mathrm{mg} /$ root. Also, in seeds germinating under osmotic stress (OS), certain inhibition of the accumulation of fresh matter in roots was evident. Despite a gradual increase in the root content of fresh matter, the values recorded after 49,72 and $96 \mathrm{~h}$ of germination were lower than in the control sample, reaching 20, 23 and $31 \mathrm{mg} /$ root, respectively. Germination under the combined cold and osmotic stresses (COS) caused the highest (relative to the control) decrease in the content of fresh matter in root tissues. The content of fresh matter after 48, 72 and $96 \mathrm{~h}$ of germination was 8, 10 and $12 \mathrm{mg} /$ root, respectively (Fig. 1).

The general ability of root tissues of germinating soybean seeds to biosynthesize proteins was investigated by analyzing the process of formation of polysomes and modifications in the composition of the total ribosomal fraction in roots. The dynamics of changes in the content of the total ribosomal fraction in roots of seeds germinating for $96 \mathrm{~h}$ is depicted in Fig. 2. The material for these analyses was collected after $24,48,72$ and $96 \mathrm{~h}$ of germination. The results were given as converted per 1 gram of fresh matter of roots. The content of the total ribosomal fraction in all the analyzed samples was the highest after $24 \mathrm{~h}$ of germination (Fig. 2). In the control roots (C), the share of the ribosomal fraction was 5.90, 4.40, 3.39 and 3.07 after 24, 48, 72 and $96 \mathrm{~h}$ of germination, respectively. In most samples of seeds exposed to cold stress (CS), the content of the ribosomal fraction per gram of root fresh matter was significantly higher at all the analyzed time intervals than in the control sample, reaching 5.95, 5.16, 4.81 and $4.27 \mathrm{mg} / \mathrm{g}$ f.m. It needs to be mentioned that after $24 \mathrm{~h}$ of germination, no significant differences were noticed between results of analyses on the effect of cold stress on the total ribosomal fraction content. In response to osmotic stress (OS), the content of the ribosomal fraction in roots from most of the samples was significantly higher than in the control, and reached 6.05, 5.14, 4.72 and $4.25 \mathrm{mg} / \mathrm{g}$ f.m. after 24, 48, 72 and $96 \mathrm{~h}$ of germination. Analogously, in the assays of seeds exposed to osmotic stress (OS), no significant differences were detected in the content of the total ribosomal fraction after $24 \mathrm{~h}$ of germination. When both stresses cooccurred, the content of polysomes in roots rose the highest, up to $6.55,5.90,5.30$ and $5.24 \mathrm{mg} / \mathrm{g}$ f.m. at the consecutive time intervals (Fig. 2).

Figure 3 shows sedimentation profiles of the total ribosomal fraction isolated from roots of seeds germinating under optimal conditions and under stresses, separated on the gradient of sucrose concentrations. Within the divisions of the total ribosomal fraction isolated from roots of 
Fig. 1 Changes in fresh weight of root tissue isolated from soybean seeds. Seeds were germinating for $72 \mathrm{~h}$ in optimal conditions (C), and long-term stress: cold (CS), osmotic (OS) and combined stresses (COS).

Data are presented as mean \pm SD. Asterisks represent statistically significant differences at $* p<0.05$ or $* * p<0.01$
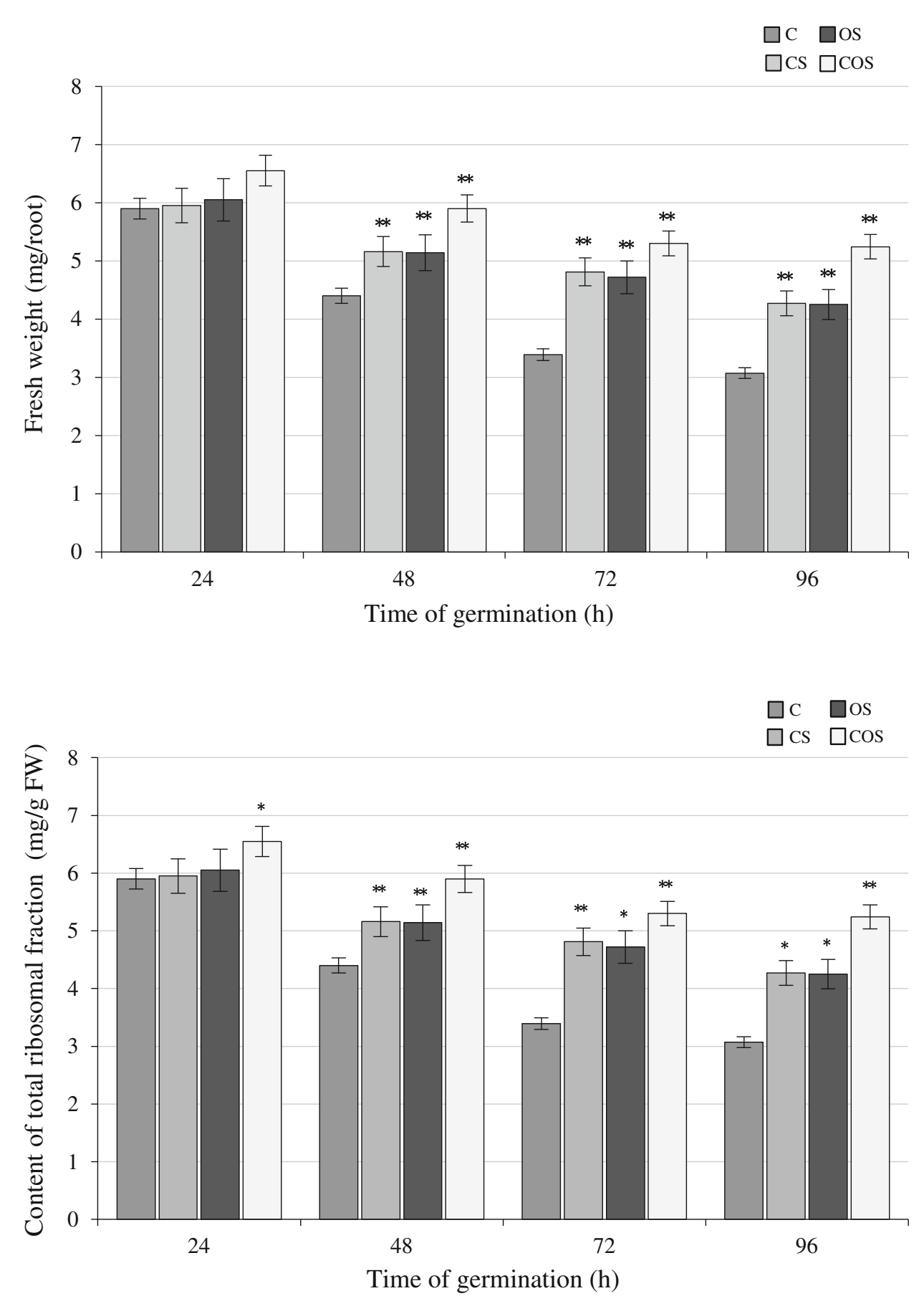

Fig. 2 Content of total ribosomal fraction in root tissues of germinating soybean seeds. Seeds were germinating for $72 \mathrm{~h}$ in optimal conditions (C), and long-term stress: cold (CS), osmotic (OS) and combined stresses (COS). Data are presented as mean $\pm \mathrm{SD}$. Asterisks represent statistically significant differences at ${ }^{*} p<0.05$ or $* * p<0.01$ germinating seeds, subunits of single ribosomes and formed polysomal complexes were found. It is worth mentioning that in dry seeds ribosomes were not observed to create polysomal complexes (data not included). After $24 \mathrm{~h}$ of germination, ribosomes made polysomal complexes in all the analyzed samples. In the control sample (C), a gradual increase in the share of polysomes during germination was observed. The percentage of polysomes in the total ribosomal fraction after 24, 48, 72 and $96 \mathrm{~h}$ of germination was $27,43,57$ and $80 \%$, respectively. Under the examined stress conditions, an increase in the share of polysomes in the total ribosomal fraction was smaller. In the sample of seeds exposed to continuous cold stress (CS), the shares of polysomes after 24, 48, 72 and $96 \mathrm{~h}$ of germination were $25,28,38$ and $41 \%$, respectively. In roots of seeds submitted to osmotic stress (OS), the percentages of polysomes determined at the same time intervals were 1 , 39,38 and $44 \%$, while in roots exposed to the combined stresses (COS), the respective contribution of polysomes to total ribosomes was 13, 14, 24 and $28 \%$ (Fig. 3). 
Fig. 3 Sedimentation profiles of total ribosomal fraction in sucrose gradient. Polysomes were isolated from roots of soybean seeds germinating for 24, 48, 72 and $96 \mathrm{~h}$ in optimal conditions (C) and under longterm continuous cold stress (CS), osmotic stress (OS) and combined stresses (COS). Subclasses of ribosomal fraction were marked with following symbols: $s$ ribosome subunits, $m$ monosomes, $p$ polysomes. Shaded area represents polysome share in total ribosomal fraction

\section{Time of germination (h)}

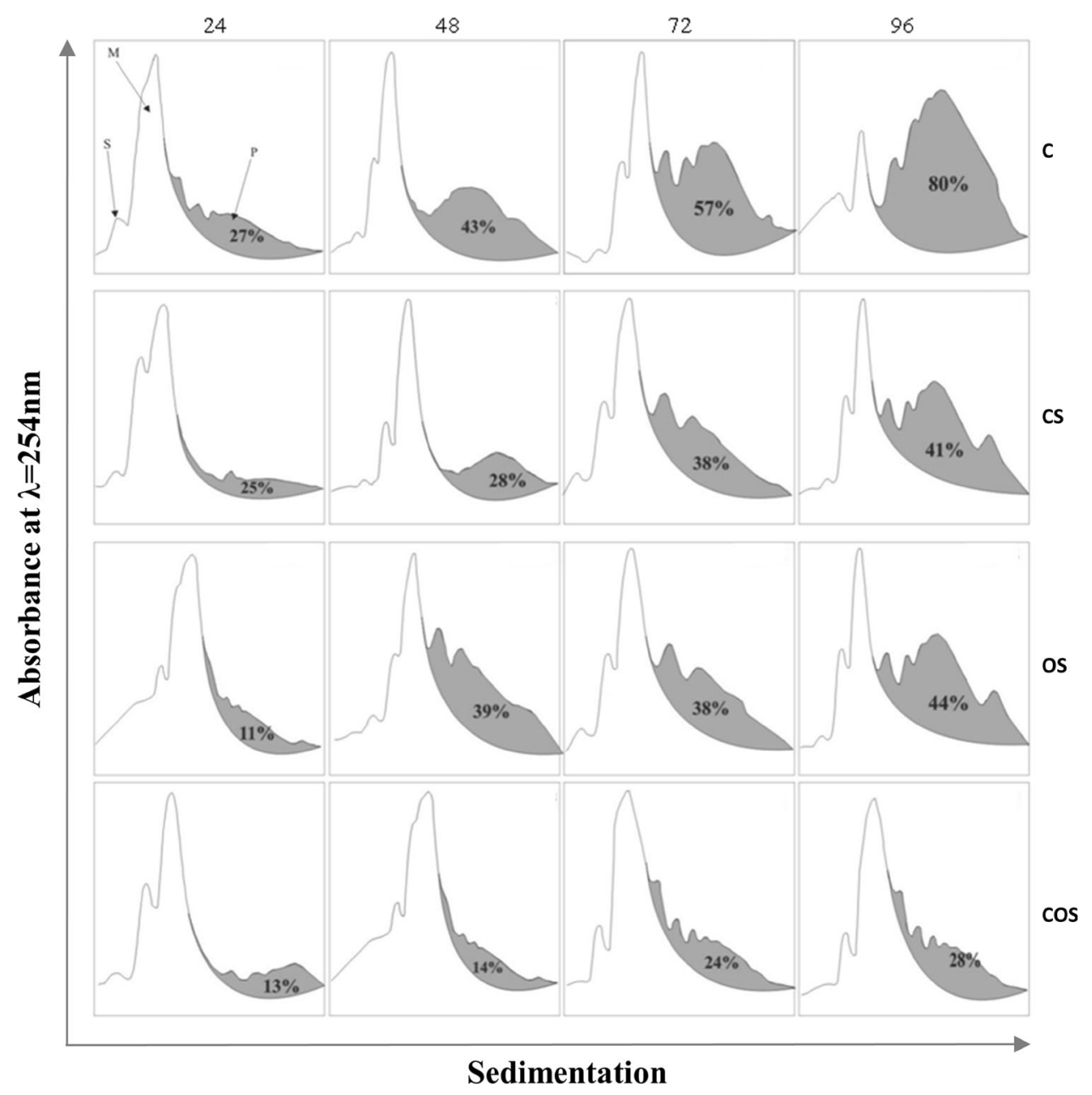

When buffers had been applied to stabilize the structure of the cytoskeleton, four fractions of polysomes became distinguishable: free (FP), membrane-bound (MBP), cytoskeleton-bound (CBP) and cytoskeleton-membrane bound (CMBP) polysomes. Figure 4 shows fluctuations in the content of particular fractions of polysomes in response to the stresses. It was determined that free polysomes (FP) were dominant polysomes in the total fraction of ribosomes in all the samples, both germinating under optimal conditions and stress-treated ones. In response to stress, a decrease in the share of FP and MBP in root tissues was observed in most samples. Parallel to that, an increase in the share of the cytoskeleton-bound (CBP) and cytoskeleton-membrane bound polysomes (CMBP) in roots was noticed.

Further analyses involved comparison of the stability of polysomal complexes in roots of germinating seeds depending on the applied abiotic stresses. To avoid unnecessary complications, analyses were performed only on roots of seeds germinating for $72 \mathrm{~h}$ under optimal conditions and under stresses. Polysomes were isolated from tissues of germinating seed roots according to the protocol described above. Sediments obtained after ultracentrifugation, which contained a total fraction of polysomes and particular populations such as FP, MBP, CBP and CMBP, were subjected to digestion by exogenous RNase. Before and after the digestion, polysomes were separated on the gradient of sucrose concentrations. Figure 5 shows sedimentation profiles of polysomes isolated from roots of soybean seeds germinating under optimal conditions and under stresses, digested and non-digested with RNase. It was found out that RNase-treated samples contained less of polysomes in the total fraction of ribosomes than samples which were not RNase digested. In the control sample (C 27), after $72 \mathrm{~h}$ of germination under optimal conditions, the percentage of polysomes in the ribosomal fraction was $57 \%$. After exogenous RNase digestion, the share of polysomes decreased by $29 \%$ (down to $28 \%$ ). In the sample exposed to cold stress (CS 72), the percentage of polysomes after RNase digestion 

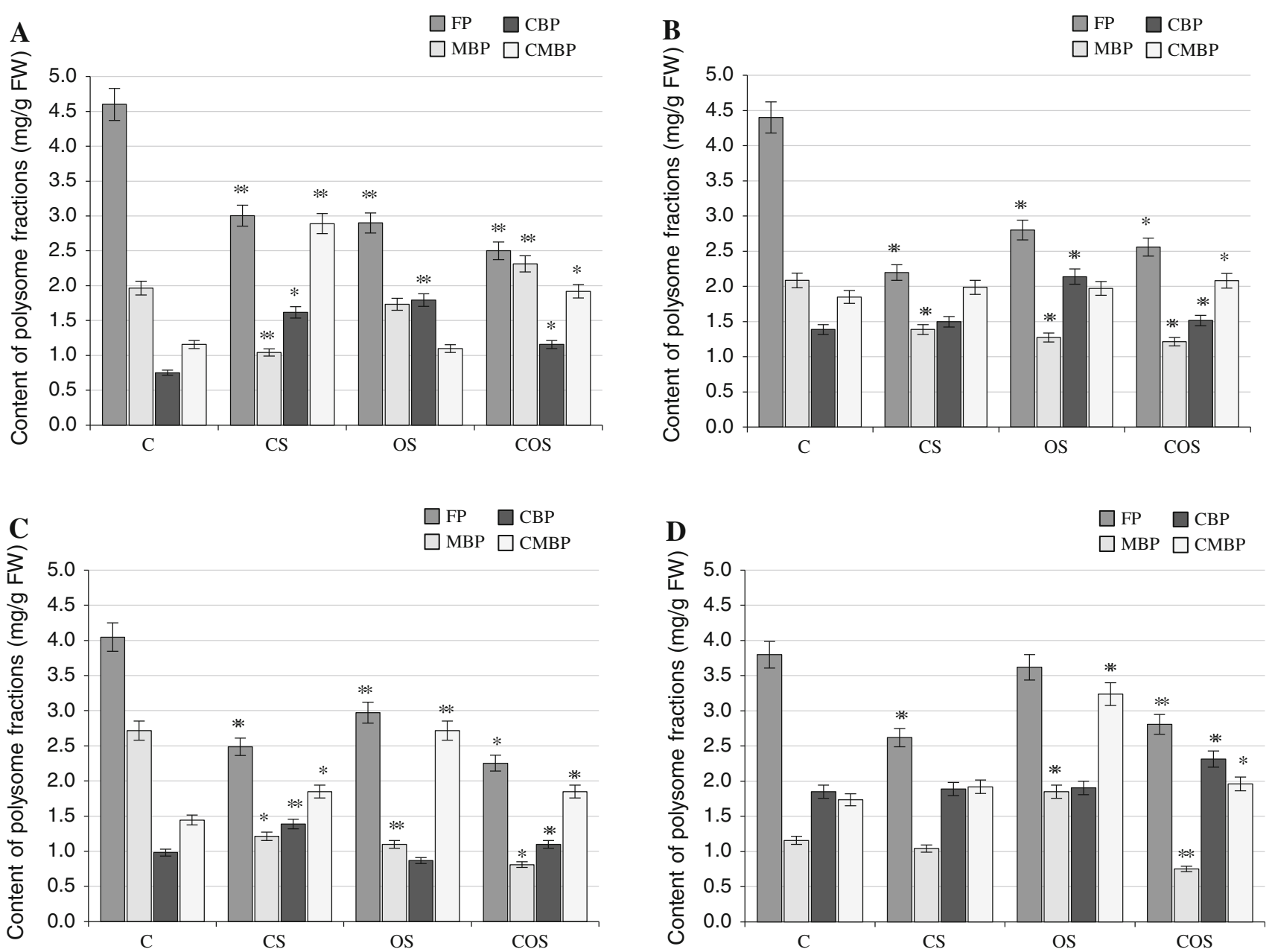

Fig. 4 Content of four polysomal fractions ( $F P$ free polysomes, $M B P$ membrane-bound polysomes, $C B P$ cytoskeleton-bound polysomes, $C M B P$ cytoskeleton and membrane-bound polysomes) isolated from root tissue of soybean seeds germinating in optimal conditions

(C) and under long-term continuous cold stress (CS), osmotic stress (OS) and combined stresses (COS) for $24 \mathrm{~h} \mathrm{(a),} 48 \mathrm{~h} \mathrm{(b),} 72 \mathrm{~h}$ (c) or $96 \mathrm{~h}(\mathbf{d})$. Data are presented as mean $\pm \mathrm{SD}$. Asterisks represent statistically significant differences at $* p<0.05$ or $* * p<0.01$

decreased by $14 \%$ (from 38 to $24 \%$ ). Polysomes were more resistant to digestion under osmotic stress (OS $72 \mathrm{~h}$ ), hence their percentage decreased by $8 \%$ (from 38 to $30 \%$ ) after RNase treatment; in samples subjected to the combined stresses (COS 72), the share of polysomes declined by app. $5 \%$ (from 24 to $19 \%$ ) due to RNase digestion (Fig. 5).

Having analyzed the stability of polysomes in the control sample, it was concluded that the percentage of polysomes undigested by RNase was $49 \%$ (Fig. 6). Compared to the control, polysomes in all the stress-exposed samples were more resistant to enzymatic digestion, for example, $63 \%$ of polysomes were not digested in a sample of seeds exposed to cold stress (CS). In seeds germinating under osmotic stress (OS), the percentage of undigested polysomes was $78 \%$ and in the sample of seeds submitted to the combined stresses (COS), it reached $79 \%$ (Fig. 6). The

higher tolerance to enzymatic digestion proves that polysomal complexes formed in soybean roots in response to abiotic stresses are more stable than the ones formed under conditions optimal for seed generation.

Differences in the stability of particular subpopulations of polysomes in roots of soybean seeds germinating under optimal and stress conditions are illustrated in Fig. 7. Once the control sample (C 72) had been digested with RNase, the pool of digestion-resistant polysomes contained most cytoskeleton-membrane-bound polysomes (CMBP), i.e., $49.5 \%$. Cytoskeleton-bound (CBP) and membrane-bound (MBP) fractions proved to be less resistant to enzymatic digestion (44.6 and $41 \%$, respectively). The least stable fraction consisted of free polysomes (FP): just $33 \%$ were not degraded by RNase digestion. It has been demonstrated that-in comparison to the control-fractions of all the analyzed, stress-exposed samples were far more stable 


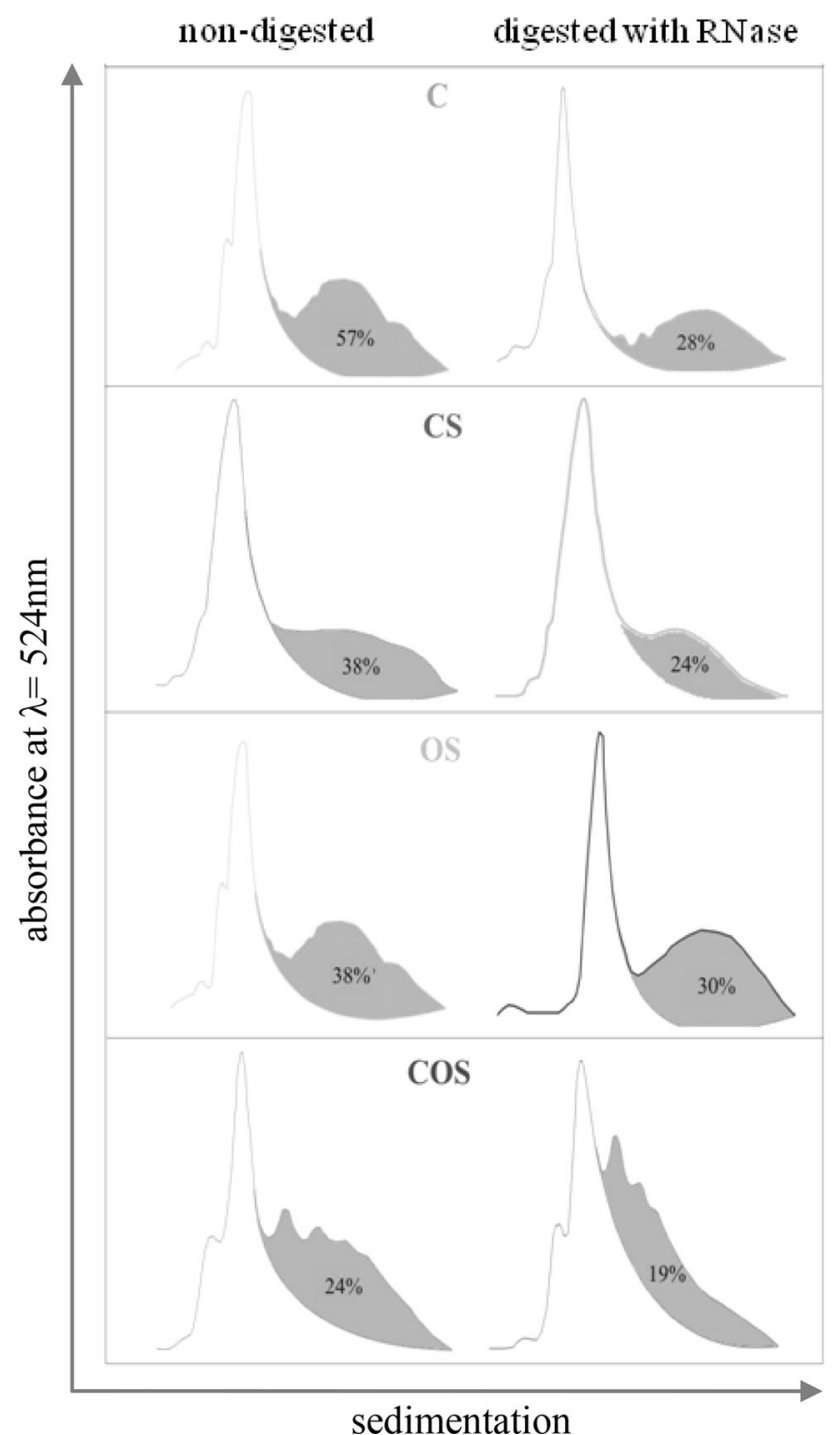

Fig. 5 Sedimentation profiles of polysomes, isolated from roots of seeds germinating for $72 \mathrm{~h}$ in optimal conditions (C) and long-term stress: cold (CS), osmotic (OS) and combined stresses (COS) before and after digestion with exogenous RNase. Shaded area of the chart indicates polysome share in total ribosomal fraction

(Fig. 7). In the sample of seeds exposed to cold stress (CS), the stability of all the four polysomal fractions was significantly higher. Percentages of undigested polysomes were as follows: $68 \%$ of cytoskeleton-bound (CBP) and cytoskeleton-membrane-bound (CMBP), $65 \%$ of membrane-bound (MBP) as well as $47 \%$ of free polysomes (FP). In the sample of seeds subjected to osmotic stress, $64 \%$ of CMBP, $52 \%$ of CBP, $49.5 \%$ of MBP and $52 \%$ of free polysomes FP were resistant to digestion. Among the polysomal fractions, $\mathrm{FP}, \mathrm{MBP}, \mathrm{CBP}$ and $\mathrm{CMBP}$, isolated from the seed sample exposed to the combined stress (COS), 63, 46, 77 and $86 \%$ of polysomes, respectively, were undigested (Fig. 7). The results of our analyses show that cytoskeleton-membrane-bound (CMBP) and CBP in all the samples were the most resistant to digestion by exogenous RNase. The other two fractions, that is, membrane-bound (MBP) and free polysomes (FP), were less stable.

\section{Discussion}

Plants are constantly exposed to stresses in the natural environment. Situations where soil and climatic conditions at the plant development key stages, for example, during germination, are perfectly suitable for a given plant species are extremely rare. The effect of low temperatures as well as soil water deficit, which may be caused by different environmental factors (draught, heat, salinity), are the major factors restricting yields of crops.

Lower temperature and osmotic stress affect germination and development of plants, disturbing most of the cellular processes (Raven et al. 2005). In our study, it has been found that cold stress, osmotic stress or a combination of both cold and osmotic stresses inhibited germination of soybean seeds and accumulation of fresh matter in seeds. Due to prolonged exposure to stress conditions, germination was considerably delayed and the length of roots of germinated seeds was significantly shorter than in seeds germinating under optimal conditions. The co-occurrence of both stresses inhibited germination more strongly than single stresses. Similar tendencies were found in previous studies (Kosowska et al. 2004; Wróbel et al. 2005; Weidner et al. 2009; Brosowska-Arendt and Weidner 2011).

Germination of soybean seeds under cold stress, osmotic stress or a combination of both cold and osmotic stresses causes changes in the process of formation of polysomes in root tissues. According to Kawaguchi et al. (2004), the extent to which ribosomes attach to transcripts and create polysomal complexes reflects the efficiency of translation ongoing in tissues. When more ribosomes bind to the mRNA transcript, the protein synthesis in a cell is more intensive. Hence, while analyzing the share of polysomes in the total fraction of ribosomes, changes in the rate of protein synthesis within tissues can be traced down (Abe et al. 2003).

The assays presented herein relined on a method of polysome analysis carried out so as to assess the capability of germinating seeds to biosynthesize proteins under optimal conditions and under stresses. The performed analysis of sedimentation profiles of the total ribosomal fraction made it obvious that formation of polysomes in roots of soybean seeds exposed to the analyzed stresses was restrained, which may indicate much lower translation efficiency in stress-treated root tissues, with the cold stress co-occurring with osmotic stress being responsible for the biggest decrease. Our results support the outcome of some 
Fig. 6 Percentage share of polysomes non-digested by exogenous RNase in total ribosomal fraction. Polysomes were isolated from roots of soybean seeds germinating for $72 \mathrm{~h}$ in optimal conditions (C) and long-term stress: cold (CS), osmotic (OS) and combined stresses (COS). Data are presented as mean \pm SD. Asterisks represent statistically significant differences at $* p<0.05$ or $* * p<0.01$
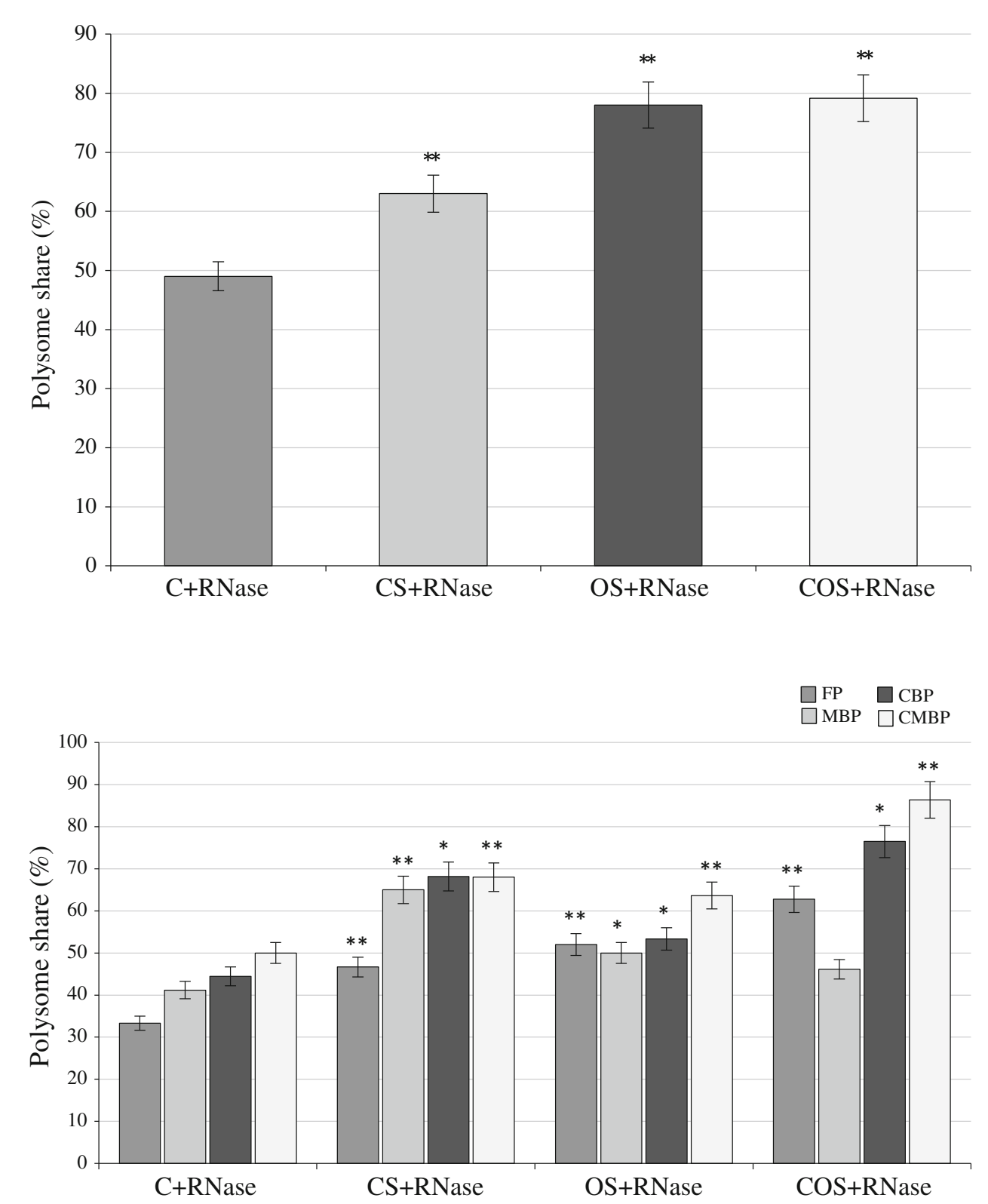

Fig. 7 Stability of polysomal fractions isolated from roots of seeds germinating for $72 \mathrm{~h}$ in optimal conditions (C) and in long-term cold stress (CS), osmotic stress (OS) and combined stresses (COS) after digestion with exogenous RNase. Data are presented as mean \pm SD. Asterisks represent statistically significant differences at $* p<0.05$ or $* * p<0.01$ earlier research on germinating seeds of rye, pea and soybean (Laroche and Hopkins 1987; Bensen et al. 1988; Kulikova et al. 2001; Slaymaker and Hoppey 2006; Brosowska-Arendt and Weidner 2011). Noteworthy is the fact that as the germination process continued, the content of total ribosomes per gram of fresh matter in roots of all samples decreased. This is closely connected with a decrease in the hydration of tissues while seed germination is advancing. As stated by Kawaguchi et al. (2004), under stress conditions large quantities of protein-coding transcripts, necessary for the normal functioning, appear in cells attached to single ribosomes. This enables rapid formation of polysomal complexes the moment a given stressor subsides; thus, quick recovery is possible.
Modifications in the formation of polysomes described in this paper pertain to the general capability of cells to carry out translation. Firstly, it was thought that all polysomes in the cytoplasm occurred in free form (Munro et al. 1964). Later, existence of at least two populations of polysomes was suggested: those bound to cellular membranes and free ones (e.g., Falk 1969). Eventually, many reports were published in which presence of forms of polysomes directly or indirectly bound to the cytoskeleton was verified (Abe et al. 1992; Zak et al. 1997; Sami-Subbu et al. 2000; Klyachko et al. 2000; Brosowska-Arendt and Weidner 2011). In the authors' previous studies, it was demonstrated that despite a general decline in the content of polysomes in roots due to stress conditions, some polysomal 
populations were synthesized even more intensively, a finding which enabled us to suspect that certain stressinduced mRNA may undergo preferential translation under stress conditions (Kosowska et al. 2004). As suggested by Kawaguchi et al. (2004), the aim of that development is to provide a sufficient supply of stress proteins. Our experiments have shown that abundance of cytoskeleton-bound (CBP) and cytoskeleton-membrane-bound polysomes $(\mathrm{CMBP})$ rose in response to stresses. Similar results were reported by Weidner et al. (2003, 2006) and Kosowska et al. (2004), who put forth a hypothesis that cytoskeletonbound proteins participate in synthesis of proteins which assist plants' acclimatization processes. This suggestion supports the claim that elements of the cytoskeleton play a key role in maintaining the translation activity of cells under abiotic stress conditions. The strategic role of the cytoskeleton in protein synthesis was later verified by other researchers (Davies et al. 1998; Klyachko et al. 2000). Interestingly, when germinating seeds were moved to optimal conditions for post-stress recovery, the number of polysomes directly or indirectly bound to the cytoskeleton decreased, while the share of free polysomes and membrane-bound ones increased (data not published herein). Based on their research results, Kulikova et al. (2001) concluded that reversible bonds between polysomes and the cytoskeleton might be one of the ways in which the process of protein synthesis was regulated.

Regulation of the expression of genes engages various mechanisms at each subsequent stage of protein biosynthesis. Transcription, post-transcription, as well as translation and post-translation protein modifications are all regulated (Zanetti et al. 2005). Translation is regulated mainly at the initiation stage (Davies et al. 1998; Kawaguchi et al. 2003). Under stress conditions, the mRNAs present in the cytoplasm undergo selective translation, which enables the cell to use up limited energy supplies to produce proteins necessary to transmit a signal, respond and adapt to stress conditions (Crosby and Vayda 1991). Green (1993) noticed that under stress conditions, mRNAs present in tissues dissociate from polysomes and undergo degradation, being supplanted by newly synthesized transcripts, coding proteins necessary for the plant to survive unfavorable circumstances. Although most mRNAs in eukaryotic cells are very stable (half-life measured in hours), some are characterized by a very active turnover (half-life 10-30 min). In some cases, the stability of polysomes is regulated (Weidner et al. 2006). This is extremely important because there is usually a simple relationship between the amount of mRNA and its translation into a specific protein. Changes in the stability of specific mRNAs may have a significant effect on biological processes. In the cytoplasm, mRNA appears in as a ribonucleo-protein complex, which is composed of ribosomes as well as many proteins which do not participate directly in translation (Bailey-Serres 1998). It has been found out that some of the proteins connected to polysomes may facilitate degradation of RNAs and polysomes, while others stabilize them by protecting ribonucleo-protein complexes from the influence of ribonucleases (Weidner et al. 2006).

The results clearly indicate that polysomes formed in roots of soybean seeds exposed to cold stress, osmotic stress or combined cold and osmotic stresses are more stable than polysomes created under optimal conditions. Higher stability of polysomes was also noticed in pea and triticale in response to an increased ABA concentration (Weidner et al. 2003, 2006) and in early pea seedlings due to shortage of water (Brosowska-Arendt and Weidner 2011). Another important factor shaping the stability of polysomal complexes seems to be the interaction of polysomes with other cellular components. As mentioned earlier, the question of an integration of ribosomes with elements of the membranes and cytoskeleton was raised in previous studies. Many researchers analyzed this type of binding in terms of the efficiency and dynamics of translation and contribution of bound polysomes into protein synthesis depending on the physiological status of a cell (Davies et al. 1998; Klyachko et al. 2000, 2003; SamiSubbu et al. 2000, Han et al. 2006; Szypulska and Weidner 2011; Brosowska-Arendt and Weidner 2012). Abe et al. (1992) described results of an experiment which indicated that the cytoskeleton-bound fraction was the most stable one among the four polysomal populations. This thesis has been supported by other scientists (Davies et al. 1998; Weidner et al. 2003, 2006; Brosowska-Arendt and Weidner 2011). Also, the results obtained in the present experiment showed that polysomal fractions bound to the cytoskeleton (CBP and CMBP) were most resistant to RNase digestion among polysomes formed in roots during the germination of soybean seeds under cold stress, osmotic stress and combined cold and osmotic stresses. One of the proposed mechanisms regulating stability of mRNA could be that under stress conditions ribosomes become more densely packed on the mRNA, thus making it more resistant to ribonuclease (Brosowska-Arendt and Weidner 2011). Brosowska-Arendt and Weidner (2012) also demonstrated that also under stress CBP were characterized by the highest translation activity, which may be indicative of an important role that this population of polysomes plays in the synthesis of stress proteins. It is worth to add that in response to osmotic stress new proteins $(22.01,96.47$ and $105.3 \mathrm{kDa}$ ), absent in the unstressed sample, were associated with the total population of polysomes. On the other hand, the protein of $22.95 \mathrm{kDa}$, which was present in polysomes of the embryonic tissue of seeds germinating under unstressed conditions, disappeared. These changes 
may have affected both the stability and the translational capacity of polysomes.

Author contribution S. Weidner prepared conception of the study, experimental design and supervised the work. S. Swigonska, A. Badowiec, A. Mostek and A. Krol performed the experiments. S. Swigonska planned the experiments, analyzed and interpreted the data and wrote the paper. All authors discussed the results and implications and commented on the manuscript at all stages.

Open Access This article is distributed under the terms of the Creative Commons Attribution License which permits any use, distribution, and reproduction in any medium, provided the original author(s) and the source are credited.

\section{References}

Abe S, Davies E (1991) Isolation of F-actin from pea stems: evidence from fluorescence microscopy. Protoplasma 163:51-61

Abe S, Ito Y, Davies E (1992) Co-sedimentation of actin, tubulin and membranes in the cytoskeleton fractions from peas and mouse 3T3 cells. J Exp Bot 43:941-949

Abe S, Azama K, Sugimoto H, Davies E (2003) Protein accumulation in the maize endosperm: role of the polyribosomes and the cytoskeleton. Plant Physiol Biochem 41:125-131

Bailey-Serres J (1998) Cytoplasmic ribosomes of higher plants. In: J. Bailey-Serres, D. Gallie, eds. A look beyond transcription: mechanisms determining mRNA stability and translation in plants. American Society of Plant Physiology, Rockville, pp 125-144

Bensen RJ, Boyer JS, Mullet JE (1988) Water deficit-induced changes in ABA, growth, polysomes and translatable RNA in soybean hypocotyls. Plant Physiol 88:289-294

Bewley JD, Bradford KJ, Hilhorst HWM, Nanogaki H (2013) Seeds: physiology of development, germination and dormancy. Springer, New York

Brosowska-Arendt W, Weidner S (2011) Effect of osmotic stress on the formation of a population of polysomes and their stability in pea (Pisum sativum L.) seeds. Acta Physiol Plant 33:1475-1482

Brosowska-Arendt W, Weidner S (2012) Effect of osmotic stress on in vitro translational capacity of polysomes and on the composition of polysome-associated proteins in germinating seeds of pea (Pisum sativum L.). Acta Soc Bot Pol 81:185-191

Cánovas FM, Dumas-Gaudot E, Recorbet G, Jorrin J, Mock HP, Rossignol M (2004) Plant proteome analysis. Proteomics 4:285-298

Chiba Y, Green Y (2009) mRNA degradation machinery in plants. J Plant Biol 52:114-124

Crosby JS, Vayda ME (1991) Stress-induced translational control in potato tubers may be mediated by polysome-associated proteins. Plant Cell 3:1013-1023

Davies E, Abe S (1995) Method for isolation and analysis of polyribosomes. Methods Cell Biol 50:209-222

Davies E, Fillingham BD, Abe S, Ito Y (1991) Evidence for the existence of cytoskeleton-bound polysomes in plants. Cell Biol Int 15:973-981

Davies E, Comer EC, Lionberger JM, Stankovic B, Abe S (1993) Cytoskeleton-bound polysomes in plants. III. Polysome-cytoskeleton-membrane interaction in maize. Cell Biol Int Rep $17: 331-340$
Davies E, Abe S, Larkins B, Clore A, Quatrano R, Weidner S (1998) The role of the cytoskeleton in protein synthesis. In: BaileySerres J, Gallie D, eds. A look beyond transcription: mechanisms determining mRNA stability and translation in plants. American Society of Plant Physiology Rockville, pp 115-124

Eulgem T (2005) Regulation of Arabidopsis defense transcriptome. Trends Plant Sci 10:71-78

Falk H (1969) Rough thylakoids: polysomes attached to chloroplast membranes. J Cell Biol 42:582-587

Funatsuki HH, Kurosaki T, Murakami S, Matsuba K, Kawaguchi S, Yumoto S, Sato Y (2003) Deficiency of a cytosolic ascorbate peroxidase associated with chilling tolerance in soybean. Theor Appl Genet 106:494-502

Gardner JC, Payne TL (2003) A soybean biotechnology outlook. AgBioForum 6:1-3

Green PJ (1993) Control of mRNA stability in higher plants. Plant Physiol 102:1065-1070

Gualerzi C, Cammarano P (1969) Comparative electrophoretic studies on the protein of chloroplast and cytoplasmic ribosomes of spinach leaves. Biochim Biophys Acta 190:170-186

Guhaniyogi J, Brewer G (2001) Regulation of mRNA stability in mammalian cells. Gene 265:11-23

Han Y, Yu J, Guo F, Watkins SC (2006) Polysomes are associated with microtubules in fertilized eggs of Chinese pine (Pinus tabulaeformis). Protoplasma 227:223-227

Kawaguchi R, Williams A, Bray E, Bailey-Serres J (2003) Waterdeficit-induced translational control in Nicotiana tabacum. Plant Cell Environ 26:221-229

Kawaguchi R, Girke T, Bray EA, Bailey-Serres J (2004) Differential mRNA translation contributes to gene regulation under nonstress and dehydration stress conditions in Arabidopsis thaliana. Plant J 38:823-839

Klyachko NL, Aksenowa L, Dunaeva M, Kulikova AL (2000) Interaction of plant polysomes with the action cytoskeleton. Cell Biol Int 24:351-358

Klyachko NL, Kulikova AL, Erokhima MA (2003) Plant polysome binding to the actin cytoskeleton as a target for physiological regulation. Cell Biol Int 27:217-218

Knapińska AM, Irizarry-Barreto P, Adsunmalli S, Androulakis I, Brewer G (2005) Molecular mechanisms regulating mRNA stability: physiological and pathological significance. Curr Genomics 6(6):1-16

Kosowska M, Frączek E, Amarowicz R, Karamać M, Abe S, Weidner S (2004) Water-deficit-induced changes in cytoskeleton-bound and other polysomal populations in embryonic tissue during triticale caryopsis germination. Acta Physiol Plant 26:67-74

Kulikova AL, Kulikov AY, Erohina MA, Klyachko NL (2001) The percentage of cytoskeleton-bound polysomes as affected by the physiological condition of plant cells. Russ J Plant Physiol 48(5):608-614

Laroche A, Hopkins WG (1987) Polysomes from winter rye seedlings grown at low temperature. Plant Physiol 85:648-654

Munro AJ, Jackson RJ, Korner A (1964) Studies on the nature of polysomes. Biochem J 92:289-299

Raven PH, Evert RF, Eichhorn SE (2005) Biology of plants, 7th edn. Freeman Worth, New York

Sami-Subbu R, Muench DG, Okita TW (2000) A cytoskeletonassociated RNA-binding protein binds to the untranslated regions of prolamine mRNA and to poly(A). Plant Sci 152: $115-122$

Slaymaker D, Hoppey C (2006) Reduced polysome levels and preferential recruitment of a defense gene transcript into polysomes in soybean cells treated with the syringolide elicitor. Plant Sci 170:54-60 
Szypulska E, Weidner S (2011) Importance of cytomatrix-bound polysomes to synthesis of lysine-containing proteins in triticale germs under ABA treatment. Acta Physiol Plant 33:1461-1465

Weidner S, Łukaszewicz D (1997) The role of free, membrane-bound and tightly bound polysomes in precocious germination of triticale caryopses. Acta Physiol Plant 19:109-118

Weidner S, Frączek E, Romanowska M, Amarowicz R, Abe S, Davies E (2003) The influence of abscisic acid on different polysomal populations in embryonic tissue during pea seeds germination. Acta Physiol Plant 25(1):5-12

Weidner S, Każarnowicz M, Frączek E, Amarowicz R, Karamać M (2006) Exogenous abscisic acid increases stability of polysomes in embryos of triticale caryopses during germination. Acta Physiol Plant 28(6):627-634

Weidner S, Kordala E, Karamać M, Kosińska A, Amarowicz R (2009) Phenolic compounds and properties of antioxidants in grapevine roots (Vitis vinifera L.) under low temperature stress followed by recovery. Acta Physiol Plant 4:279-286
Wróbel M, Karamać M, Amarowicz R, Frączek E, Weidner S (2005) Metabolism of phenolic compounds in Vitis riparia seeds during stratification and during germination under optimal and low temperature stress conditions. Acta Physiol Plant 27(3A): 313-320

Zak EA, Sokolov OI, Greengauz OK, Bocharova MA, Klyachko NL (1997) Polysomes from Vicia faba L., leaves bound to the actin cytoskeleton. J Exp Bot 48(310):1019-1026

Zambetti G, Wilming L, Fey EG, Penman S, Stein J, Stein G (1990) Differential association of membrane-bound and non-membranebound polysomes with the cytoskeleton. Exp Cell Res 191: 246-255

Zanetti ME, Chang IF, Gong F, Galbraith DW, Bailey-Serres J (2005) Immunopurification of polyribosomal complexes of Arabidopsis for global analysis of gene expression. Plant Physiol 138: 624-635 